\section{Optimizing healthy ageing in disadvantaged communities: insights into older people's use of health and social care services}

\author{
Josephine Tetley \\ The Open University, Walton Hall, Milton \\ Keynes, UK
}

\section{Abstract}

The European Year of Healthy Ageing recognizes that health care systems need to be improved and reorganized if services are to optimize the opportunities for people to stay healthy and well in their own homes for as long as possible. However, current services tend to be fragmented and insensitive to the needs of older people and their carers resulting in services being underused or refused leading to increased admissions into acute hospital care that could have been prevented. The main aim of the study reported in this paper was to identify the factors that affected older peoples' decision and choice-making processes, when using or contemplating the use of care services. Using a constructivist methodology, this study used participant observation and 23 interviews in three study settings: an African Caribbean support service, day centers for people with memory and cognition problems and luncheon clubs for older people. An inductive analysis of the data revealed that when older community dwelling people found themselves struggling with certain aspects of their daily care needs; they used adapting, coping and seeking as strategies to manage. Additional issues of how well services were able to meet individual's aspirations for care and support were identified through themes of match-mismatch, fair-unfair, independence-dependence. The findings reported in this study provide important insights as to how people's needs are complex yet are negatively affected by rigid state controlled services that ultimately affect individual decisions to use or refuse services.

\section{Introduction}

The year 2012 has been designated as the European Year of Healthy Ageing., ${ }^{1,2}$ Within this, improving and reorganizing care for older persons in modern health systems has become a priority underpinned by three main themes: prevention, equity of access and an adequate supply of quality care. ${ }^{2}$ While these are laudable aims, designing effective services for community-dwelling older people across
Europe has historically been difficult because social and community care needs are poorly understood and have been affected by political and ideological shifts in the development of community care policies. ${ }^{3,4}$ Indeed, in the United Kingdom the ideology of long term care for older people has shifted from institutional care to a focus on the development of services and interventions that enable older people to remain at home for as long as is possible. ${ }^{5}$ However, the political achievement of this goal has varied as governments have struggled with the debates around state versus individual funding for care and support. This has resulted in a range of reports and government papers that have put forward various models and suggestions as to how care and support for older people can be provided. .-8 $^{6}$

Inquiries and commissions into the funding and means testing for care and support in later life may be important for the development of government policies, but the reports and recommendations tend to focus on macro issues of who pays for what and in what circumstances and not individual experiences of services. It is important to recognize this as studies of needs assessment and service delivery have found that, in everyday practice, older people are not consulted and are often presented with limited choices and unattractive services. ${ }^{9-11}$ Moreover, older people report that having limited control over decision-making about access to and use of care services compromises their independence, sense of self and quality of life. ${ }^{12,13}$ As a consequence, in spite of policy and service developments intended to promote and support ageing in place, older people still tend to under-use the services that are intended to support them. ${ }^{14,15}$ Understanding why people do not always use the full range of support available is particularly important for nurses who play a crucial role in supporting older people in their own homes and working to coordinate care that can prevent unplanned admissions to hospital. ${ }^{16}$ While older people may make a decision to not use services that they feel do not meets their needs, other studies and reports have further identified that the situations and contexts in which people find themselves making decisions and choices also affects their involvement. For example, a review of the literature around older people's preferences for long term care and a UK task group review of support for older people found that people with dementia are more likely to be excluded from decision-making processes. ${ }^{17,18}$ A longitudinal study of older people's preferred sources of help and a review of what older people with high support needs value further identified that limited personal financial resources reduce choice options. ${ }^{19,12}$ Reviews of research and policy also found that lack of cultural sensitivity within mainstream services limits choices for elders from black and minority eth-
Correspondence: Josephine Tetley, The Open University, Walton Hall, Milton Keynes, MK7 6AA, UK. Tel: 01908858931.

E-mail: josie.tetley@open.ac.uk

Key words: decision and choice making, older people, community services, healthy ageing.

Funding: this research was funded by NHSE Trent.

Received for publication: 13 August 2012.

Revision received: 13 September 2012.

Accepted for publication: 14 September 2012.

This work is licensed under a Creative Commons Attribution NonCommercial 3.0 License (CC BYNC 3.0).

(C) Copyright J. Tetley, 2012

Licensee PAGEPress, Italy

Nursing Reports 2012; 2:e11

doi:10.4081/nursrep.2012.e11

nic communities. ${ }^{20,21}$

While the literature identifies factors that might impact on older people's choice and decision-making processes, the studies of older people's use of care and support services have tended to focus on one issue, and have not explored broader issues of service design and delivery in the context of multiple service user groups. In contrast, this paper reports findings from a constructivist study that was developed to explore older people's experiences when they found themselves needing help and support to manage some aspect of their everyday lives taking into account of issues of ethnicity, dementia and socio-economic status.

\section{Materials and Methods}

\section{Aim}

The main aim of this study was to identify the factors that affected older people's decision and choice-making processes, when using or contemplating the use of care services.

\section{Methods}

A constructivist approach was used to guide the study. A constructivist approach was particularly relevant for the intended study as this recognized the importance of participatory working and power sharing. ${ }^{22}$ Moreover, nurses, social workers and public sector employees who have used a constructivist approach within their work argue that the real value of this approach is that it promotes holistic personcentered working. It achieves this by enabling the inquirer to understand how the relation- 
ships between the biological, physiological, socio-cultural and spiritual dimensions affect individuals perceptions of their needs for care and support. ${ }^{22-25}$

\section{Study design}

The introduction to this paper identified that older people with mental capacity issues, from the black and minority ethnic communities, and those with limited personal financial resources were more likely to experience particular problems when they requested care and support from health and social care support services. Work with these groups could therefore provide potentially useful insights for those purchasing and providing health and social care services in relation to the abilities of care and support services to meet the individual and collective needs of these groups.

In selecting a location for qualitative inquiries Marshall and Rossman ${ }^{26}$ suggested that realistic study sites should be able to provide the researcher with a point of entry, a rich mix of people, interactions and processes, the possibility of building up relationships and trust with potential participants and the opportunity to gather credible data. I therefore took the proposed research to three well established organizations, in a large multicultural city in the north of England, for further discussion. These were:

A charitable organization that provides day care, outreach and support for people and carers affected by memory and cognitive problems;

A day centre and outreach service for black elders attached to a large community centre established by the African Caribbean community;

A network of luncheon clubs coordinated by a charity that works to support and provide adult education for older people.

All three organizations gave a positive response to the proposed research. Each organization identified key areas where they delivered their services on a regular basis that they felt would enable me to meet a broad range of service users.

The study was granted ethics approval from the a National Health Service ethics committee in the UK.

\section{Data collection}

Consistent with a constructivist approach the study was undertaken using participant observation, interviews and personal narratives. ${ }^{22,27,28}$ Participant observation and interviews were used as data based on words and observations are more adaptable and capable of dealing with multiple realities and expose more clearly the nature of transactions between the investigator and participants. ${ }^{29}$ Through the participant observation, purposive sampling took place over 14 months across the three settings to identify participants to interview who could represent multiple realities. As a result, 24 people were identified whose stories illustrated a range of perspectives and experiences related to how they had made decisions and choices about the services that they used or refused to use. The interviews took place either at the venue that the older person was visiting or in their own home. Each interview took between one and three hours. Following each interview, a narrative summary of the experiences shared by each person was constructed drawing on the participant observation data and interview transcripts. The narrative summaries were then shared the participants. Working in this way gave people the opportunity to read and make sense of their experiences in the context of the study and further reflect and comment on their biographies and personal stories. ${ }^{30}$ These narratives also provided a whole picture of the person and their stories which provided a rich context and background to the inductive analysis process that followed. An inductive analysis of the interview data was undertaken following the narrative analysis as this enabled the data collected to go beyond individual stories and accounts and transform raw data into themes and categories that bring broader understandings to the investigation. ${ }^{31}$ The analysis process used to develop and identity the themes and categories is now outlined.

\section{Analysis}

Consistent with a constructivist approach, the analysis of the interview transcripts was undertaken using a constructivist data analysis processes of unitizing and categorizing..$^{32,22}$ Unitizing was used to code the interview transcripts into units of analysis that could be understood without further explanation, i.e. they are able to stand alone. ${ }^{22,32}$ Using this process across 24 transcripts, 786 data units were initially created.

Following the process of unitizing, categorizing was then used as a process to bring the initial coding units together to form categories. Within categorizing two processes of sorting and lumping took place.

Sorting was used to bring the initial data units together to identify relevant themes or categories. Using sorting a descriptive framework of factors that appeared to affect individual decision-making processes was developed.

This was followed by lumping when similar units were then brought together to form provisional categories. These processes were then continued until clear relationships between the categories started to emerge.

\section{Findings}

Using the data analysis processes five key categories were initially identified: i) recognizing there was a problem; ii) thinking about support or help; iii) applying for or contacting services and support systems; iv) using services and support systems; v) continuing with or exiting from services and support systems.

As these categories emerged from the data units, I wrote memos to record the decisions to develop and link categories. For example one of the first key categories initially identified was recognizing that there was a problem. However, looking at the transcripts and codes it became clear that recognizing that there was a problem did not always mean that people would use care services. One of the first linking memo's written was called managing-struggling (Table 1).

These processes were used to analyze all 23 interviews until eventually five categories emerged: i) managing-struggling; ii) adapting, coping and seeking; iii) match-mismatch; iv) fair-unfair; v) independence-dependence.

An overview of the themes is given in Table 2.

The experiences reported by the older people are now presented using the key themes to illustrate how these impacted on their decision-making processes when they were using or contemplating using a range of health and social care services. Quotes from participants have been purposefully selected to demonstrate how people's lived experiences related to the emergent themes and categories. All participants have been given pseudonyms to protect their identities. The use of first names or surnames in the pseudonyms reflects how each person wished to be addressed when I met and interviewed them.

\section{Managing or struggling}

Managing or struggling were a consistent factor throughout many people's stories. Being able to get by without help or support was particularly important to the people that I met and interviewed. So, although everyone interviewed was accessing some form of care or support service, people also often described the areas of their lives they were able to manage without help.

For example, a woman who was supported by the African Caribbean outreach service spoke about the things she was still able to manage for herself:

That's two things I'm glad for. I can cook a bit of dinner for myself and I can wash me clothes and keep myself clean.

[Mrs Harris, African Caribbean Outreach Service]

Being able to manage was also important for people to remain in their own home. When I interviewed Mr Smith from the luncheon club I went to his flat. On my arrival I had to climb a very steep set of stairs. I was aware that $\mathrm{Mr}$ Smith had poor mobility so asked him if the stairs were a problem. He replied:

Well when I was in hospital the consultant mentioned this and said, what about these 
stairs, going up. Oh I said I manage.

Fortunately they've got two rails and I can manage all right, which I can. I don't have any problem going up and going down.

[Mr Smith, Luncheon Club]

In another example when I asked Lucy, a woman with dementia, if she thought she could manage at home without the services that she received, she replied:

Yes, I could, and I argue about that, I can manage. Even if they take my legs off I can still manage. I'd still jump off my backside to go.

[Lucy, Dementia Day Centre]

It was interesting to note that although Lucy spoke broadly about her ability to manage, other people were talking about their ability to independently manage their needs in relation to activities of daily living and instrumentalactivities of daily living, including personal finances. Indeed Laura from the luncheon club spoke about her ability to manage her

\section{Table 1. Managing-struggling (memo).}

\section{Linked to tree nodes}

Recognizing there was a problem

Managing problems

Health

Support from family-friends-others

Independence

\section{Recogniving that there was a problem}

Mrs H recognized that she has problems and talked about how her situation at home is:

.... a struggle sometimes I'm better than sometimes. I wasn't, the day before I wasn't very good I had to I were lying down all *** and I just feel sleepy all the time sometime I feel... yesterday were too wasn't too well but yesterday today's not too much of a good day for me.

Mrs $\mathrm{H}$ also talked about struggling to get undressed in the evening; she only had home care services in the morning.

I made a comment about my own struggle to get my shoes and socks off (because of my pregnancy).

She then commented:

Mrs H: Yes all right but soon you finish it but I've got to do it all the time.

Having to do it all the time - think about having to manage even though situation a struggle.

In some situations, however, people became unable to manage. J (who cared for her mother who had dementia) explained the circumstances that surrounded her decision to accept a placement at a day care centre for her mother:

... at that time I wasn't getting any sleep or anything, it was really, really bad.

Managing a struggle therefore makes me think that the decision to use care services is related to trade-offs and balances between two competing tensions, in this case managing or struggling. So people will try to manage a difficult situation without help but when struggling outweighs managing this is likely to act as a prompt to seek or accept additional help and support.

\section{Table 2. Key themes.}

\section{Managing-struggling}

When struggling outweighed managing this led to people:

Recognizing there was a problem with health or managing some aspect of their life at home.

People described how they tried to bring their situation back into managing by:

Adapting - their lifestyle of physical environment;

Coping - by drawing on inner strength and or religious beliefs;

Seeking - lay or professional help.

\section{Adapting-coping-seeking}

People described how they tried to bring their situation back into managing by:

Adapting - their lifestyle of physical environment;

Coping - by drawing on inner strength and or religious beliefs;

Seeking - lay or professional help.

\section{Match-mismatch}

When people were struggling they sought help to bring their situation back into managing:

There could be a match or mismatch between the availability/ability of personal and environmental resources to meet the persons perceived needs;

Mismatch with formal/statutory services was affected by assessment processes, service availability, service quality, eligibility criteria.

\section{Fair-unfair}

People saw access to services or benefits as fair or unfair:

A judgment of unfair was made when others seen as less deserving get services/benefits, or when access to services did not take account of people's prior contributions to society in general.

\section{Independence-dependence}

People wanted to be independent but accepted being dependent on services if they:

Alleviated the struggle;

Met their needs;

Promoted independence in some other way;

Enabled them to stay in their own home. 
finances:

What I do, I have everything paid by direct debit. My hubby did it, set it up, and I do that, and I find out I've got a budget, by the way these are off now. I've a budget that I pay and it keeps it all right. I've put me water on a meter to save money for that, I've got me telephone on a lightusers scheme, and I pay for me gas, me lights, I've got standing orders for me gas, me electricity, me phone, me water, and I pay the insurance for me house monthly. Because when it comes to $\$ 300$ or $\$ 400$ you just don't have it. I budget it out so that I've got enough money in the bank to cover them all, and as I said, we're going away so I save [whispering - I've got little banks all over], and I put me money in so that, you know, I'm alright.

[Laura, Luncheon Club]

Other people similarly described how they managed their finances. But when I interviewed Mr Jenkins from the luncheon club he explained how he saw managing his finances as important to help secure his long-term independence:

I've put so much away, and because I've got such an income coming in, because I've got so much put away if I needed help like to go into a home or something like that, I would have most of that taken away from me so I try to be as independent as I can and as long as I can.

[Mr Jenkins, Luncheon Club]

Using the analysis process described, I started to see that people more commonly talked about managing or struggling in the context of situations where they recognized that there was a problem. Table 3 gives an overview of the issues with which people were struggling.

Closer examination of the categories and stories revealed how people then adopted strategies that they hoped would bring their situations back into managing; these were adapting, coping and/or seeking help. Having identified these three strategies, I then used them to scrutinize the interview transcripts in order to explore how individuals described their use of each strategy.

\section{Adapting, coping, seeking}

Harry from the luncheon club was severely disabled by his emphysema, which had worsened over the last few years. As he explained to me:

Well when we first came here I could walk more, I could almost run up this incline up to the flat. But as time's gone on I've got worse, and now I have to do it in three easy stages to get up to here.

I usually come up to the top of that thing, I push myself right to the top of it and I have a rest there, then I come into here, and I usually have to sit on the steps in the hallway. I usually sit on that bottom step until I get my breath back. Because I just can't come in and put a key in a lock, you know, I'm so out of breath. It's amazing, it really is how you need your breath.

[Harry, Luncheon Club]

What this demonstrated was that Harry recognized that the struggle with his health problems outweighed his ability to manage. Harry went on to explain that he had tried to bring his situation back into managing by adapting and buying an electric scooter. Unfortunately this didn't help. When the scooter was delivered he realized that the steps from his flat prevented him getting it onto the pavement or the road. Because this strategy didn't alleviate the struggle Harry then used seeking, as he sought professional help in an attempt to bring his situation back into managing. He explained that he had contacted the city council to see if they would build a ramp on the pavement.

Anyhow I rang them up and she said. I gave her all the details of what it was and then she said, well we're very busy at present, it will be at least 12 weeks before we can get round to you. So I said, oh fair enough, I'll just have to wait. Anyhow, bang on the 12 weeks I got a telephone call and they said, they were glad I'd rang up and all this that and the other, and were things still the same, so I said, yes. So eventually this person came... she measured all around and looked all around, and then before she went she said, well we've got all your details but it's got to go through the manager's office before we can start on anything, so it might be a little while. I think it was about 3-4 weeks went by and I got a letter. That's the first one I got... No, I'm telling a lie, I got a telephone call before that letter and then she said, this person that had been to measure up said that it was going into the top manager's office the following week. And fair enough, in round about a week she telephoned me again and said they've granted your... you can have the thing made. So she said but it will be a while I think. And then I got a letter about a week after that that said that it would be 6 months.

[Harry, Luncheon Club]

This example illustrated how when Harry sought help to bring his situation back into managing by adapting, he could only do this by seeking help from professional care workers. However, when he sought help Harry did not know how the professionals would assess his request or his situation at home. He also had no idea that resources were limited and that it would eventually take a year for the work to be undertaken to adapt the pavement. So whilst Harry's decision to seek help eventually brought him back towards managing, there was a delay in the ability of professionals and statutory services to meet his request.

In another example, Mrs May was similarly struggling to manage at home because of problems related to her rheumatoid arthritis. When I interviewed her she told me that when her
Table 3. Struggling to manage.

People spoke about struggling to manage

Activities of daily living

Bathing/showering

Getting dressed/undressed

Personal appearance

Walking around

Instrumental activities of daily living

Cooking

Shopping

Housework

Managing steps/stairs

Gardening

Health problems related to

Memory/behaviour

Diabetes

High blood

Breathing

Arthritis

\section{Financial issues}

Manage on benefits/pension

Cost of transport

arthritis first affected her she was initially able to manage because her husband was alive and he was able to do the cooking, housework and gardening. As she explained:

He did all this decorating and everything, he'd have a go at everything. He tiled the bathroom and, you know. You see that's why I'm lost. We never paid for somebody to come and do it because he could do it. Well now I'm sort of in limbo. And one of the hardest things was, he took over the kitchen when he retired. It's only a tiny kitchen and there weren't rooms for two of us so I left him to it in the finish. Well he did all the cooking. Well I was lost when he'd gone, and I didn't cook for ages. And I don't do a lot of cooking now. Not like I used to do before he took over. You see and he took over the washing and ironing, and even just before he died he said, will you show me how to iron best shirts. He could iron everything else but his own shirt I used to try and do what I could. I could perhaps be better now, but I couldn't stand up very long then.

[Mrs May, Luncheon Club]

She explained that after her husband died a combination of adapting, coping and seeking had brought her situation back to managing. For example, in relation to adapting she told me how she now managed to cook for herself:

And just recently I've tried to do some myself. I've bought a slow cooker and I've got a sandwich maker, and then I've bought a thing what they call a browning thing, you can put 
sausages and bacon and things on it in the microwave and it browns them. But all that is easier for me, I can't mess about cutting meat up or anything like that, you know. I'm not a right big meat eater.

[Mrs May Luncheon Club]

Mrs May had also sought professional advice from her general practitioner who had helped her obtain the attendance allowance which enabled her to pay for additional support to help her manage her shopping and cleaning. She explained:

Well whenever I go to the supermarket I have a taxi back. If I go down to the Parks /local shopping complex] or even onto the Spar, I can't carry shopping so I always have a taxi back. And when I go to my son's on Thursday I have a taxi from town to his house. I do a bit of shopping at bottom of town, and then I pay my cleaner, I have a cleaner every week for a couple of hours.

[Mrs May, Luncheon Club]

She also explained that after her husband had died she went to see her family doctor and told him that she felt isolated, like on an island really. Following this her doctor suggested that she should try a luncheon club. She said:

The doctor said I should go to a Luncheon Club. Well I didn't know anything about them and he [her doctor] said he would get in touch with Social Services, they got in touch with me and they didn't seem... I'm saying Social Services... yes it was. They didn't seem to know anywhere, they didn't seem to know anything about it. And I don't know how it [came] about. There's a little place [where] they used to have coffee mornings, and I went in one day and I was talking about things and they lady said, oh we have a Luncheon Club at Tuesday. Well I went there and then through the person I sit next to she said, would you like to come Monday, I'll get your name down. And then like six months after I'd gone to Tuesday Club I went to the Monday Club.

[Mrs May, Luncheon Club]

When I asked Mrs May how she coped with the physical jobs around the house after the death of her husband, she told me:

Well to be honest all I can say is I've just had to manage. And I get days when I can't do anything, and then where there are days I feel better I have to just get on with it. But I have this young woman comes every Friday and does the bulk of the work. I can't hoover, I can't possibly use the hoover. And well she does really a lot of work for me.

[Mrs May, Luncheon Club]

While the situations described by Harry and Mrs May demonstrated how they used adapting, coping and seeking as strategies for managing the difficulties they encountered, the analysis of their interviews revealed that adapting and coping had only partly brought their situations back into managing and they had both had to seek help from others to more fully resolve their problems. While adapting coping and seeking worked for some people, when other people talked to me about their experiences they did not always found that the services available met their aspirations for help and support. Match-mismatch therefore emerged as another key theme from the interviews.

\section{Match-mismatch}

When I interviewed Mr Maxwell from the African Caribbean day centre I was aware that he was struggling to care for his wife at home. When I asked him how he was managing at home he said:

Whatsoever is to be done, it's me who's got to do it. One of the times when I realized that it was a bit too much for me, I went round seeking help but couldn't get none, so I've got to still struggle with her. And then I went down here and asked, the most thing they want to do is shopping, and there's nothing much we want at shop but they just want to do shopping, they just want to spend the money.

What they want is to get her, wash her, that's all and do shopping, but I can wash her and if anything the little bit that we want of shopping I can just jump in the car and go and buy it from [the supermarket] and come back. So a lot of those people what they say, is more they can do, but they cannot hoover and they don't allow to hoover nor do anything more.

[ $\mathrm{Mr}$ Maxwell, African Caribbean Day Centre]

So whilst home care was available, the service they offered did not match his aspirations for help. When he finally accepted the support from mainstream home care, he found himself stopping the service as he later told me the quality of the care they provided was poor. As a consequence of not being able to get the care and support that he wanted, Mr Maxwell described how he had finally become psychologically and physically ill:

I was really broken down, really, really broken down, and then everything just built up on me and then it drove my blood pressure right up and my sugar was gone right up, through the worries and all those things coming back.

[ $\mathrm{Mr}$ Maxwell, African Caribbean Day Centre]

Because social services homecare was unable to meet his needs for care and support, Mr Maxwell was eventually offered support through the specialist home care service provided by the African Caribbean day centre where I had met him. He described how this was a more flexible service and therefore better able to resolve some of his problems:

The good thing they help with is ironing, the little help that I'm getting now is very good and I quite appreciate it.

[Mr Maxwell, African Caribbean Day Centre]
He went on to explain that the worker from the specialist service also spent time with his wife:

She comes she goes upstairs and she sits down with my wife and talks and comforts her and they sit down and talk.

[Mr Maxwell, African Caribbean Day Centre]

The issue of match and mismatch between lay aspirations and service availability was reflected in other interviews. For example, Mrs Harris described how home care services assisted her with her hygiene and dressing needs but they were no longer able to provide support or help for other household tasks as she explained:

Well what they had, they always let two home helps come to help me clean but they don't again, they cut them service off now.

[Mrs Harris, African Caribbean Outreach Service ]

Because a head and neck injury meant she was not able to manage the hoover, she had to ask her son to help when he visited her.

A man from the dementia day centre further described how he could not get any help maintaining his garden:

... but it's trying to get something out of the council, you haven't got a chance. Like Linda yesterday said, oh I'll get somebody to cut all that grass dad. I'd like to do it myself, but it's one of them things, I can't. .

[Terry, Dementia Day Centre]

Where people found themselves struggling with these tasks and did not have the support of family or friends, the mapping process highlighted that when people found themselves struggling and services were not available, this led to those who could afford it paying for private help and support. When I interviewed Harry from the luncheon club I was aware that he was barely able to walk so I asked how he managed his cleaning. He explained that he paid a friend to help:

I pay her. She actually asked for $\$ 2.50$ an hour I think it was when she first came, and I said I can't pay you that little bit for coming and cleaning. Anyhow she takes $\$ 10$ away every time she goes now.

[Harry, Luncheon Club]

Harry, however, like Mrs May was only able to afford the cost of a private cleaner because he received the attendance allowance, which his family doctor had helped him obtain:

He used to say how's your cleaning going on, and he asked me once when I were in I said, it's getting a bit of a bind. I said it's only half getting done just now. So he gave me a telephone number and he said, ring that number and tell them you need some help at home. So I rang this number and they sent me a form to fill in and anyway this money, I get [every] week. And I got it... anyhow somebody was talking to me about it, I think it was the doctor or somebody 
down there and they said, well you pay for your cleaning out of that, she said, and other stuff, not for your medicine or for your food she says, it's for other things. So that's how I do it.

[Harry, Luncheon Club]

So in situations where health and social care services were not able to meet the care needs that the individual wanted meeting, people either had to pay for private services, which may first require them to apply for benefits, or as in Mr Maxwell's case continue to struggle.

\section{Fair-unfair}

People were also deterred from applying for services and benefits because, to be eligible, they had to prove how disabled they were. Mrs Purdy from the African Caribbean day centre had been thinking of applying for aids and adaptations to help her get in and out of the bath but was put off by the application form as she explained:

The forms that they sent me just said you've got to be very disabled, and I'm not very disabled but I'm disabled, and I didn't bother with it and it's still at home there.

[Mrs Purdy, African Caribbean Day Centre]

The notion of not being disabled enough was interesting as from the analysis of my research notes and interviews it became clear that use and uptake of services was affected by the extent to which they saw the assessment and eligibility criteria as fair or unfair. Indeed a woman from the luncheon club told me about caring for her husband who had a long-term problem with his health. She explained that they had tried to manage without help or support. But having seen other people successfully get mobility support, they decided to apply for this benefit. She then described their unsuccessful experience of applying for this:

And the doctor said, oh, your car's lovely and bright. So I said it ought to be, I've just washed it. Oh. I said you don't think he's done it do you? And the doctor went and he shook hands with Leonard and said so long to me then we got the paper back, it wasn't necessary for us. You see we had tried to do the best we could we couldn't have it. So I was naughty and I said I want to look at the report, and do you know why we were turned down? Leonard had got a firm handshake and the handshake, his hands were the strongest part of him. And we applied again and they phoned me up, from Leeds, and said we're sorry, but you're not eligible to any money at all. So I just said well tell them to keep it I've just buried my husband. She went Oh Oh. I said don't Oh Oh me, I said I'm bitter with you lot and I put the phone down.

[Laura, Luncheon Club]

As a result of this experience Laura told me that she would find it difficult to apply for help or services in the future and would:

... like to think there was a service that I could call upon to help and I would like to think I wouldn't have to go through a doctor and a committee in which to get that help.

[Laura, Luncheon Club]

Negative experiences and perceptions of assessment processes and eligibility criteria therefore deterred people from applying for benefits and services that may help them when they found themselves struggling with some aspect of their health or care needs.

\section{Independence-dependence}

The theme of match-mismatch illustrated how Mr Maxwell from the African Caribbean day centre finally agreed to receive home care services that did not meet his aspirations because he accepted that he needed help. Having traded-off his aspirations against this recognition Mr Maxwell found himself rejecting the service not only because they did they not meet his needs, but because the quality of the service was so poor. Other people, however, described how they continued to accept services that did not always meet their needs. For example, Mr Smith from the luncheon club described some of his problems with the home care service:

You have some are better than others, you know, but sometimes they come early and that sort of thing, and I mean for tea-time sometimes they come at 3:00. Well I mean I've only just had my lunch, you know, and I have to refuse them.

[Mr Smith, Luncheon Club]

When I asked him how he felt about this he said:

It's far better than going in a nursing home. I prefer it.

[Mr Smith, Luncheon Club]

Others similarly commented on the variability of the quality of the home care workers who visited them in their homes. When I visited Mrs Harris from the African Caribbean day centre in her home I met her home care worker who had been out to shop for her. After she left I asked her about her experience of the home care service to which she replied:

They make my bed and change it and they help me to get a shower and help me get dressed and they might peel me potato, me cabbage and their out. Some will do pots but some don't. But this one comes and she ever so good she helps me a lot. I haven't got the energy to do me pots but when she comes she regardless of how many pots she'll wash me pots but some of them they just... make my bed, help me get into the shower and help me get dressed and just peel potato and through the door. Some of them are not very..., not very.... nice really.

[Mrs Harris, African Caribbean Outreach Service]

A woman from the dementia day centre also commented how:

The one at the minute is a bit bossy at the moment, but I just don't take any notice of her.
I just let her get on with it. You've got to be very careful I know all about it. I say, oh yes, yes. Oh and I look as if butter wouldn't melt in my mouth, you know. I mean I've had changes, all of them are very nice, very nice indeed. And there's one fellow that comes... oh there's Gerald who's a young man that comes, and African, he's lovely, I like him.

[Trudi, Dementia Day centre]

So, although the home care service was not always good, people described having to tradeoff and accept the short fallings of a service in order to remain in their own homes.

\section{Discussion}

A recurring issue throughout the study was how changes to health and social care services have limited or stopped state funded services providing support, particularly for low level care needs. The findings however, revealed that older people's needs are diverse, complex and cannot easily be met though health and social care services that primarily focused on providing care and support for activity of daily living needs. Indeed, the story of Mr Maxwell particularly highlighted how, as a carer, he wanted to wash and dress his wife and have support for housework instead. Constraints on service provision, however, prevented this from happening. The issue of service inflexibility were reflected in findings from the Joseph Rowntree Older People's Research Programme,${ }^{18}$ which concluded that:

There is a paradox of sorts in that older people may be offered a service they don't want while they cannot get access to a service that they do want. Sometimes the mismatch is in terms of agreeing or not agreeing with the assessment of need. But at other times it seems that resources are still locked up in services that don't do what people want or in service practices that don't meet people's needs ( $p 37$ ).

Brindle $^{33}$ also argued that community care initiatives should look at ways of generating more imaginative integrated care and support from neighbors and community groups. However, to be successful the findings of the research suggest that local authorities must redesign their services based on older people's, family carers' and communities' expressed needs. The European Year of Health Ageing ${ }^{1,2}$ also wants service redesign to focus on prevention, equity of access and an adequate supply of quality care. In a move towards achieving this, in the United Kingdom, there has been a move towards personalization where individuals, as opposed to health and social care professionals, hold their own budget, assess their own needs and make decisions about the resources that are purchased to meet those needs, ${ }^{34}$ While these are seen as positive 
moves, nurses and social workers have identified that managing a budget and purchasing services may be more difficult for older people who are already struggling to manage their own needs. ${ }^{35,36}$ However, despite the challenges to implementing personalization it is recognized that giving people more control over what services they use to support them in their own homes is the most significant shift towards person-centered practice becoming a reality. ${ }^{35,36}$

In terms of achieving personalization at the level of the individual older person, the findings of my study are important as the interviews identified that where services were able to be more flexible and meet people's expressed needs. This more commonly occurred when the interventions were provided by charities or specialist community support services. The dementia care charity and black African Caribbean service both appeared to have better understandings of the needs of the people they were serving and were prepared to be more flexible about the support they provided. Unfortunately people's decision and choice-making options to use these were affected by the limited funding available or rigid local authority service contract agreements, which restricted the eligibility criteria and range of services that could be provided. As a consequence any needs that the specialist services could not meet resulted in people having no other choice but to use mainstream services that were less able to meet their needs.

More recently voluntary and community groups in the UK have been more broadly defined as The Third Sector, in an attempt to unite these groups and formalize their relationship with the state. ${ }^{37,38}$ Current government policy related to involvement with the third sector has also outlined its intention to partner with voluntary and community care services wherever possible as they recognize these organizations have strong and effective links with the communities that they aim to serve. ${ }^{39}$ In addition to this partnership working, there is an intention to capitalize on the notion of social enterprise where charities are recognized as small businesses that create employment opportunities for people whilst also providing a service for vulnerable people. ${ }^{40}$ Whilst the luncheon club network, African Caribbean day care service and the dementia charity support services were all positive examples of third sector services supporting older people with low level care needs, the findings of my research revealed that they were successful because they were able to be flexible and creative. The recognition that charities and community groups can provide more flexible and acceptable services for older people in the community may, however challenge nurses and social care workers who may have to relinquish some of their traditional roles to others. Moreover, as new services emerge and develop nurses and social care workers supporting older people in their own homes may find it increasingly difficult to keep abreast of the range of services that are available. In terms of transferability of the findings from this study to a more global context, international studies and comparisons have identified that there is much variation in the range and scope of providing and funding services. ${ }^{41}$ Sharing research findings that illustrate community services seem best able to meet older people's needs is therefore important as this can inform debates as to which models and innovations in community practice are more likely to meet the needs of older people whose needs are not easily met by traditional and mainstream services.

\section{Conclusions}

This study found that the factors affecting older people's use and uptake of community care services involve a complex mixture of factors as older people want to maintain independence while recognizing they need help and support. Moreover, there are clearly individual differences in how these operate. However, rigid state controlled services were less effective in meeting people's needs than more specialist community based services that understood the needs of the people and community that they were working with. By undertaking research with older people whose decision and choicemaking options are already limited by issues related to health, finances and ethnicity, this study provided important insights into their lived experiences as they attempted to remain in their own homes for as long as they possibly could. These insights should be an invaluable form of evidence for nurses and social care workers, as they illustrate individual and collective needs that future planning and redesign of services should aspire to respond to if they are going to maximize the potential for older people to remain in their own homes for as long as possible.

\section{References}

1. Boeckxstaens P, De Graaf P. Primary care and care for older persons: position paper of the European forum for primary care. Qual Prim Care 2011;9:369-89.

2. European Commission. Taking forward the strategic implementation plan of the European innovation partnership on active and healthy ageing. Brussels, $\operatorname{COM}(2012) 83$ final of 29.2.2012. Available from: http://ec.europa.eu/ health/ageing/ docs/com_2012_83_en.pdf

3. Nafstad HE, Carlquist E, Blakar RM Community and care work in a world of changing ideologies. Community Work Family 2007;10:329-40.

4. Leichsenring K. Integrated care for older people in Europe-latest trends and perceptions. Int J Integrat Care 2012;12:1-4.

5. Sixsmith A. Sixsmith J. Ageing in place in the United Kingdom. Ageing Int 2008;32:219-35.

6. Sutherland $\mathrm{S}$. With respect to old age: long term care - rights and responsibilities. A report by The Royal Commission on long term care. London: The Stationary Office; 1999.

7. Wanless D. Wanless social care review: securing good care for older people: taking a long term view. London: Kings Fund; 2006.

8. Dilnot A, Warner N, Williams J. Fairer care funding: the report of the Commission on Funding of Care and Support. Volume I. London: Commission on Funding of Care and Support; 2011.

9. Aronson J. Elderly people's accounts of home care rationing: missing voices in long-term care policy debates. Ageing Soc 2002;22:399-418.

10. Blood, I. Older people with high support needs: how can we empower them to enjoy a better life. York. Joseph Rowntree Foundation; 2010.

11. Young J, Turnock S. Community care waiting lists and older people. $\mathrm{Br}$ Med J 2001;322:254.

12. Katz J, Holland C, Peace S, Taylor E. A better life - what older people with high support needs value. York: Joseph Rowntree Foundation; 2011.

13. Forbes S, Hoffart N. Elders' decision-making regarding the use of long-term care services: a precarious balance. Qual Health Res 1998;8:736-50.

14. Baldock JC, Hadlow J. Self-talk versus needs-talk: an exploration of the priorities of housebound older people. Qual Ageing Policy Pract Res 2002;3:42-8.

15. Care Quality Commission The state of health care and adult social care in England: an overview of key themes in care 2009/2010. London: The Stationary Office; 2011.

16. Grange M. How community matrons perceive their effectiveness in case management. Nurs Older People 2011;23:24-9.

17. Kane RL, Kane RA. What older people want from long-term care, and how they can get it. Health Affairs 2001;20:114-27.

18. Joseph Rowntree Foundation. From welfare to well-being - planning for an ageing society. York: Joseph Rowntree Foundation; 2004. 
19. Wenger GC. Choosing to pay for care. 26. Marshall C, Rossman GB. Designing qualHealth Soc Care Commun 1999;7:187-97.

20. Atkin K. Ageing in a multi-racial Britain: demography, policy and practice. In: Bernard M, Phillips J (eds). The social policy of old age. London: Centre for Policy on Ageing; 1998. pp 163-182.

21. Moriarty J. The health and social care experiences of black and minority ethnic older people: better health briefing number 9. London: Race Equality Foundation; 2008.

22. Rodwell M. Social work constructivist research. London: Garland; 1998.

23. Engebretson J. Littleton LY. Cultural negotiations: a constructivist-based model for nursing practice. Nurs Outlook 2001;49: 223-30.

24. Laughlin R, Broadbent J. Redesigning fourth generation evaluation: an evaluation model for the public-sector reforms in the UK. Evaluation 1996;2:431-51.

25. King L, Appleton JV. Pearls, pith and provocation: fourth generation evaluation of health services: exploring a methodology that offers equal voice to consumer and professional stakeholder. Qual Health Res 1999;9:698-710. itative research. 3rd edition. Thousand Oakes: Sage; 1999.

27. Ellis C, Bochner AP. Autoethnography, personal narrative, reflexivity: researcher as subject. In: Denzin NK, Lincoln YS (eds). Handbook of qualitative inquiry. 2nd edition. Thousand Oaks: Sage; 2000. pp 733768.

28. Guba EG, Lincoln YS. Fourth generation evaluation. Newbury Park: Sage; 1989.

29. Silverman D. Interpreting qualitative data: methods for analyzing talk, text and interaction. London: Sage; 2006.

30. Tetley J, Grant G, Davies S. Using narratives to understand older people's decision-making processes. Qual Health Res

31. Thomas DR. A general inductive approach for analyzing qualitative evaluation data. Am J Eval 2006;27:237-46.

32. Lincoln YS, Guba EG. Naturalistic inquiry. Beverly Hills: Sage; 1985.

33. Brindle D. Care and support - a community responsibility. York: Joseph Rowntree Foundation; 2008.

34. Department of Health. A Vision for adult social care: capable communities and 2009;19:1273-83. active citizens. London: Department of Health; 2010.

35. Morgan S. Opportunities and risks of personalisation. Nurs Manage 2010;17:14-7.

36. Phillips T, Goehing C, Shaw I, Oram J. Personalisation, support brokerage and social work - what are we teaching social work students? J Soc Work Pract 2010;24: 335-49.

37. National Audit Office Home Office. Working with the third sector. London: The Stationary Office; 2005.

38. Treasury HM. The future role of the third sector in social and economic regeneration: interim report. London: The Stationary Office; 2006.

39. Department of Health. Caring for our future: reforming care and support. London: The Stationary Office; 2012.

40. European Commission. Health and longterm care in the European Union. Special Eurobarometer 283. Brussels; 2007. Available from: http://ec.europa.eu/public_opinion/archives/ebs/ebs_283_en.pdf

41. Genet N, Boerma WGW, Kringos DS, et al. Home care in Europe: a systematic literature review. BMC Health Serv Res 2011;11: 207. 